\title{
Improvement of urethral resistance after the administration of an alpha-adrenoceptor blocking agent, urapidil, for neuropathic voiding dysfunction
}

\author{
T Yamanishi MD,${ }^{1} \mathrm{~K}$ Yasuda MD, M Tojo MD ${ }^{1} \mathrm{~T}$ Hattori MD,${ }^{2} \mathrm{R}$ Sakakibara MD ${ }^{2}$ \\ J Shimazaki MD ${ }^{1}$ \\ Departments of ${ }^{1}$ Urology and ${ }^{2}$ Neurology, School of Medicine, Chiba University, 1-8-1 \\ Inohana, Chuo-Ku, Chiba-city, Chiba, Japan.
}

\begin{abstract}
We assessed the effect of a new alpha-blocking agent, urapidil, on neuropathic voiding dysfunction, by urodynamic studies. The residual urine volume and rate significantly decreased, whereas the average and the maximum flow rate did not increase significantly. The pressure at maximum flow and minimum urethral resistance decreased significantly. These results suggest that improvement of the voiding dysfunction in some cases could be due to the decreased micturition pressure without increasing the flow rate. The urethral resistance calculated from the pressure/flow data seemed to be a valuable index in evaluating the effects of the drug on neuropathic voiding dysfunction.
\end{abstract}

Keywords: urapidil; urethral resistance; alpha-blocker; neuropathic bladder.

\section{Introduction}

Alpha-adrenoceptors are known to be present predominantly in the bladder base, posterior urethra and prostate. ${ }^{1}$ Alphablocking agents are reported to reduce the urethral resistance and improve the voiding dysfunction caused by neurological disorder $^{2}$ or benign prostatic hyperplasia $(\mathrm{BPH}){ }^{3}$

Alpha-blocking agents have been reported, especially in $\mathrm{BPH}$, to effectively improve the average flow rate (Qave) and maximum flow rate (Qmax) and reduce the residual urine volume and residual urine rate. ${ }^{4}$ The reduction in urethral resistance is suggested from the decrease of the maximal urethral closure pressure and prostatic urethral pressure in the urethral pressure profile, ${ }^{5}$ which reflect, however, only the urethral pressure at rest. Minimal urethral resistance $(\mathrm{R})$, calculated from pressure/ flow $(\mathrm{p} / \mathrm{f})$ parameters by using the $\mathrm{R}=$ PQmax/Qmax ${ }^{2}$ (PQmax: pressure at maximum flow) formula is often used as an index representing dynamic urethral resistance during voiding. ${ }^{6}$

Kleeman ${ }^{7}$ investigated the effect of an alpha-blocker, phenoxybenzamine (POB), by means of $\mathrm{p} / \mathrm{f}$ study in seven male and five female dogs. He found that ephedrine, norepinephrine and phenylephrine increased urethral resistance, whereas POB inhibited these effects, but he could not demonstrate the reduction in urethral resistance by POB.

Gerstenberg et $a l^{8}$ studied the effect of $\mathrm{POB}$ in patients with $\mathrm{BPH}$ and reported the significant increase in Qmax and significant decrease in PQmax and minimal urethral resistance.

Krane $e t a l^{9}$ reported the effectiveness of POB on the neuropathic bladder, but they did not evaluate the drug urodynamically. Jensen et $a l^{10}$ reported an improvement of uninhibited contraction using prazosin (Minipress ${ }^{\circledR}$, Phizer, Japan), but they did not report the improvement in voiding difficulty. Cramer et $a i^{11}$ reported the usefulness of the bladder neck opening test (measurement of the bladder neck diameter in voiding cystourethrography) and measurement of the posterior urethral pressure (pressure at the middle portion between the bladder neck and the external urethral sphincter) during voiding as a means to evaluate the effect of alfuzosin (a 
new alpha-blocker) in patients with a spinal cord injury. The measurement of the posterior urethral pressure seems to be meaningful for the calculation of urethral resistance during voiding, but it is difficult to use it as a routine procedure because the catheter should be fixed in a precise position under $\mathrm{x}$-ray monitoring. ${ }^{12}$ There have been few other reports on the efficacy of alphablockers in voiding difficulties of the neuropathic bladder patients because it is very difficult to determine standard parameters in the disease which includes supra- and infranuclear types of voiding dysfunctions.

The authors investigated the effect of urapidil (Ebrantil ${ }^{\circledR}$, Kaken, Japan), a new alpha-blocker, on the voiding dysfunction of the neuropathic bladder by performing $\mathrm{p} / \mathrm{f}$ studies.

\section{Patients and methods}

Fourteen male and 15 female patients with neuropathic bladder (aged 61.4 \pm 13.7 years) were studied. The underlying diseases were brain diseases (seven patients, $24.1 \%$ ), spinal cord diseases (six patients, $20.7 \%$ ), peripheral nervous system diseases (15 patients, $51.7 \%$ ) and brain disease associated with spinal cord disease (one patient, 3.4\%) (Table I). Cystometry

Table I Causative neurological disease

$\begin{array}{lll}\text { Brain disease } & & \\ \quad \text { Cerebrovascular disease } & (24.1) \\ \text { Spinal cord disease } & & \\ \text { Cervical cord injury } & 2 & (6.9) \\ \text { Spastic paraplegia } & 1 & (3.4) \\ \text { Cervical spondylosis } & 1 & (3.4) \\ \quad \text { Subarachnoiditis } & 1 & (3.4) \\ \quad \text { CNS lupus } & 1 & (3.4) \\ \text { Peripheral nervous system disease } & & \\ \quad \text { Cauda equina lesion } & 4(13.8) \\ \quad \text { Postoperative rectum cancer } & 4(13.8) \\ \quad \text { Postoperative cervical uterine } & 4(13.8) \\ \quad \text { cancer } & 3(10.3) \\ \quad \text { Diabetic neuropathy } & \\ \text { Brain and spinal cord disease } & \\ \quad \text { Cerebrovascular disease } & \\ \quad \text { Cervical spondylosis } & & \end{array}$

Numbers in brackets denote \%.
(CMG) before treatment showed a normal bladder in three patients $(10.3 \%)$, detrusor hyperreflexia in six $(20.7 \%)$, low compliance bladder in $13(44.8 \%)$ and detrusor areflexia in seven $(24.1 \%)$. In an external sphincter electromyography (ES-EMG), detrusor-external sphincter dyssynergia (DSD) was noted in 11 patients $(37.9 \%)$.

Uroflowmetry (UFM) was performed in the standing or the sitting position, and the average flow rate (Qave) and maximal flow rate (Qmax) were measured. After UFM, a $12-\mathrm{F}$ two-way catheter was inserted transurethrally for the measurement of the residual urine volume (RU). The residual urine rate (RUR) was calculated from the measured residual urine in the following formula: RUR $(\%)=(\mathrm{RU} /$ (voided volume $+\mathrm{RU})) \times 100$. Water CMG and ES-EMG were carried out in the lithotomy position. When the patient felt a maximal sensation or when the instillation reached $600 \mathrm{ml}$ of water, the catheter was replaced with a $4-\mathrm{F}$ pigtail catheter (Cook Co.) (Fig 1), and the $\mathrm{p} / \mathrm{f}$ measurements were carried out in the same position as UFM. In each study, the baseline zero pressure was adjusted to the upper border of the symphysis pubis. In the $\mathrm{p} / \mathrm{f}$ studies, opening pressure (OP), maximum pressure (Pmax) and pressure at maximum flow (PQmax) were measured in accordance with the criteria of ICS. ${ }^{13}$ The minimal urethral resistance $(\mathrm{R})$ was calculated by the following formula: $\mathrm{R}=$ PQmax/Qmax ${ }^{2}{ }^{6}$

The patients were treated with urapidil in a dose of $30 \mathrm{mg} /$ day for the first 2 weeks.

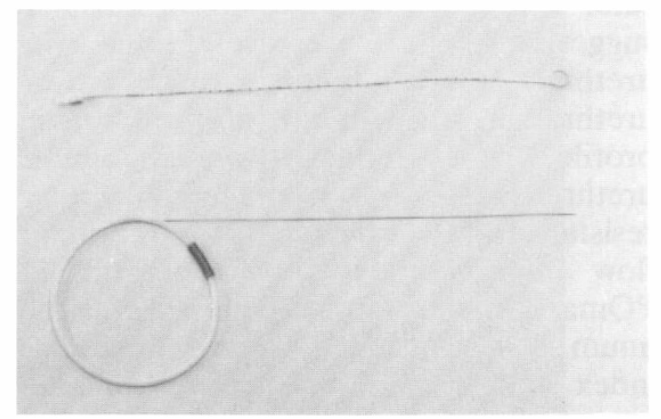

Figure $14-F$ pigtail catheter and teflon coated wire guide (Cook Co.). 
Patients without satisfactory improvements in symptoms were treated at $60 \mathrm{mg} /$ day for a further 2 weeks. For patients with satisfactory improvements, the dose was not changed during this 2 week period. The effect of the drug was evaluated mainly from the changes in minimal urethral resistance (R) by calculating the $\mathrm{p} / \mathrm{f}$ study. The urinary symptoms were scored on a 4-grade scale to assess the symptomatic improvement as reference data for the evaluation of the clinical effect (Table II).
Lastly, a paired $t$-test was used for a statistical analysis of the urodynamic data.

\section{Results}

Symptomatic improvement (Table III)

The total symptom score was $7.3 \pm 3.6$ before the treatment and $3.2 \pm 2.6$ after the treatment $(p<0.01)$. The improvement in symptom score by 3 or more was noted in 16 cases $(55.2 \%)$.

Table II Urinary symptoms before treatment with urapidil (according to questionniares)

\begin{tabular}{lclr}
\hline Symptoms & Scores & Grades & Patients (\%) \\
\hline Hesitancy & 3 & Severe & $6(20.7)$ \\
& 2 & Moderate & $4(13.8)$ \\
Prolongation & 1 & Minimum & $12(41.4)$ \\
& 0 & None & $7(24.1)$ \\
& 3 & Severe & $6(20.7)$ \\
Urinary stream & 2 & Moderate & $8(27.6)$ \\
& 1 & Minimum & $12(41.4)$ \\
& 0 & None & $3(10.3)$ \\
Straining & 3 & Severe & $4(13.8)$ \\
& 2 & Moderate & $15(51.7)$ \\
& 1 & Minimum & $8(27.6)$ \\
Sensation of incomplete voiding & 0 & None & $2(6.9)$ \\
& 3 & Severe & $5(17.2)$ \\
& 2 & Moderate & $4(13.8)$ \\
& 1 & Minimum & $13(44.8)$ \\
& 0 & None & $7(24.1)$ \\
& 3 & Severe & $7(24.1)$ \\
& 2 & Moderate & $8(27.6)$ \\
& 1 & Minimum & $5(17.2)$ \\
& 0 & None & $9(31.0)$ \\
\hline
\end{tabular}

Table III Changes in symptom score and $\mathrm{R}$ after administration of urapidil

\begin{tabular}{|c|c|c|c|c|c|}
\hline & \multicolumn{5}{|c|}{ Changes in symptom score } \\
\hline & $\begin{array}{l}\text { Reduced by } \\
5 \text { or more }\end{array}$ & $\begin{array}{l}\text { Reduced by } \\
3 \text { or } 4\end{array}$ & $\begin{array}{l}\text { Reduced by } \\
1 \text { or } 2\end{array}$ & $\begin{array}{l}\text { Unchanged or } \\
\text { increased }\end{array}$ & Total $(\%)$ \\
\hline \multicolumn{6}{|l|}{ Changes in $R$} \\
\hline $\begin{array}{l}\text { Reduced by } 50 \% \text { or } \\
\text { more }\end{array}$ & 5 & 3 & 5 & 2 & $15 \quad(51.7)$ \\
\hline Reduced by $30-50 \%$ & 3 & 0 & 1 & 0 & $4 \quad(13.8)$ \\
\hline Reduced by $10-30 \%$ & 1 & 0 & 2 & 0 & $3 \quad(10.3)$ \\
\hline $\begin{array}{l}\text { Reduced by less than } \\
10 \% \text { or increased }\end{array}$ & 4 & 0 & 1 & 2 & $7 \quad(24.1)$ \\
\hline Total (\%) & $13(44.8)$ & $3(10.3)$ & $9(31.0)$ & $4(13.8)$ & $29(100.0)$ \\
\hline
\end{tabular}




\section{Results of $p / f$ studies}

The changes in Qave (from $4.0 \pm 3.1 \mathrm{ml} / \mathrm{s}$ to $4.5 \pm 2.8 \mathrm{ml} / \mathrm{s}, n=27$ ) and Qmax (from $10.3 \pm 5.7 \mathrm{ml} / \mathrm{s}$ to $11.5 \pm 5.9 \mathrm{ml} / \mathrm{s}, n=28)$ were insignificant. RU (from $128.7 \pm$ $96.7 \mathrm{ml}$ to $85.6 \pm 105.6 \mathrm{ml}, \quad n=29)$ and RUR (from $42.7 \pm 22.5 \%$ to $30.1 \pm 23.9 \%$, $n=28)$ significantly decreased $(p<0.05$, $p<0.01$, respectively) (Fig 2 ). In $\mathrm{p} / \mathrm{f}$ studies, OP (from $74.0 \pm 27.9 \mathrm{cmH}_{2} \mathrm{O}$ to $\left.67.0 \pm 30.2 \mathrm{cmH}_{2} \mathrm{O}, \quad n=28\right)$ and Pmax (from $87.3 \pm 33.6 \mathrm{cmH}_{2} \mathrm{O}$ to $81.1 \pm 37.2$ $\mathrm{cmH}_{2} \mathrm{O}, \quad n=28$ ) showed no significant changes, but PQmax (from 78.0 \pm 30.9 $\mathrm{cmH}_{2} \mathrm{O}$ to $\left.65.5 \pm 26.8 \mathrm{cmH}_{2} \mathrm{O}, n=29\right)$ and $\mathrm{R}$ (from $2.5 \pm 3.1$ to $1.2 \pm 1.8, n=29$ ) significantly decreased $(p<0.05, p<0.01$ respectively) (Fig 3).

$\mathrm{R}$ was reduced by $30 \%$ or more in 19 cases $(65.5 \%)$, including 11 cases $(37.9 \%)$ associated with symptomatic improvement by three points or more as symptom scores. In the remaining eight cases $(27.6 \%)$, $\mathrm{R}$ was improved, but not to a significant degree the symptoms. In another five cases $(17.2 \%)$, symptom scores were improved, but not with an improvement in R. There was no correlation between the change in $\mathrm{R}$ and in symptom scores (Table III). In a stratified analysis, there were no differences in the improvement of $\mathrm{R}$ between sexes, underlying diseases, patterns in CMG before treatment and the presence or absence of DSD.

\section{Discussion}

Alpha-blocking agents have been known to reduce urethral resistance, and to be effective regarding neuropathic voiding dysfunction and urethral obstruction due to benign prostatic hypertrophy. There have been, however, no published reports on the reduction of urethral resistance $(\mathrm{R})$ based on the $\mathrm{p} / \mathrm{f}$ study on the neuropathic bladder. $\mathrm{R}$ itself is calculated being based on the supposition that the urethra is a rigid pipe. Strictly speaking, the $\mathrm{R}$ calculated as above does not represent the real urethral resistance. ${ }^{14}$ This parameter, however, is consistent with the clinical status and it seems to be useful to assess the therapeutic effects of drugs where $p / f$ data are used in the same
Average flow rate $(n=27)$

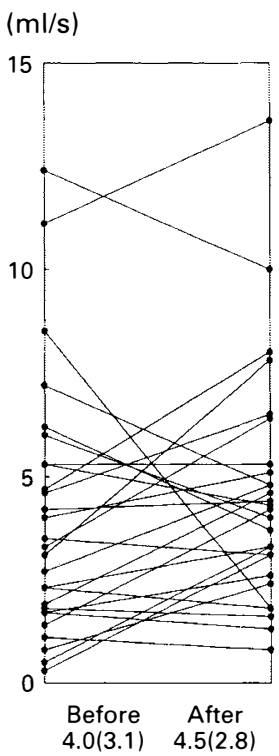

Maximum flow rate $(n=28)$

$(\mathrm{ml} / \mathrm{s})$

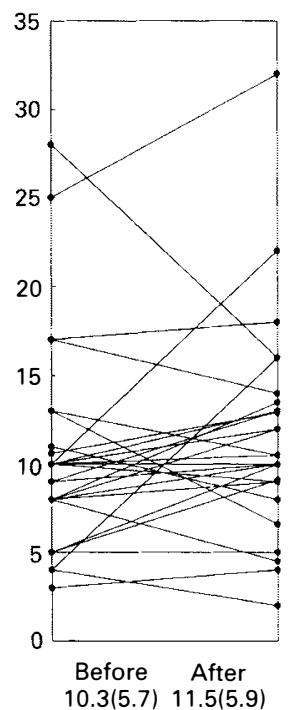

Residual urine volume $(n=29)$

(ml)

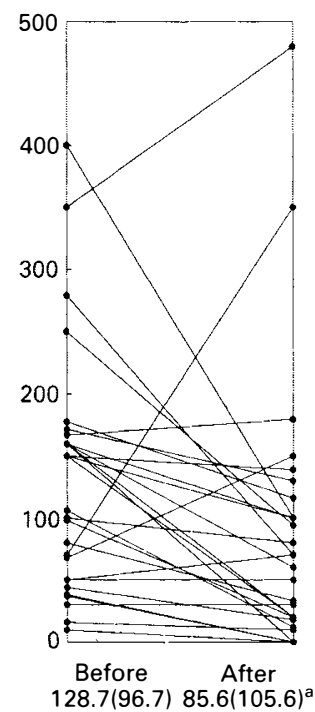

Residual urine rate $(n=28)$

(\%)

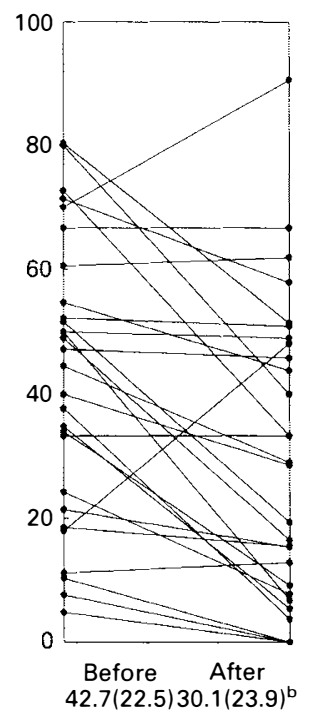

Figure 2 Changes in uroflowmetry and residual urine before and after treatment with urapidil. Values are mean (SD). ${ }^{\mathrm{a}} p<0.05 ;{ }^{\mathrm{b}} p<0.01$ (before and after treatment, paired $t$ test). 

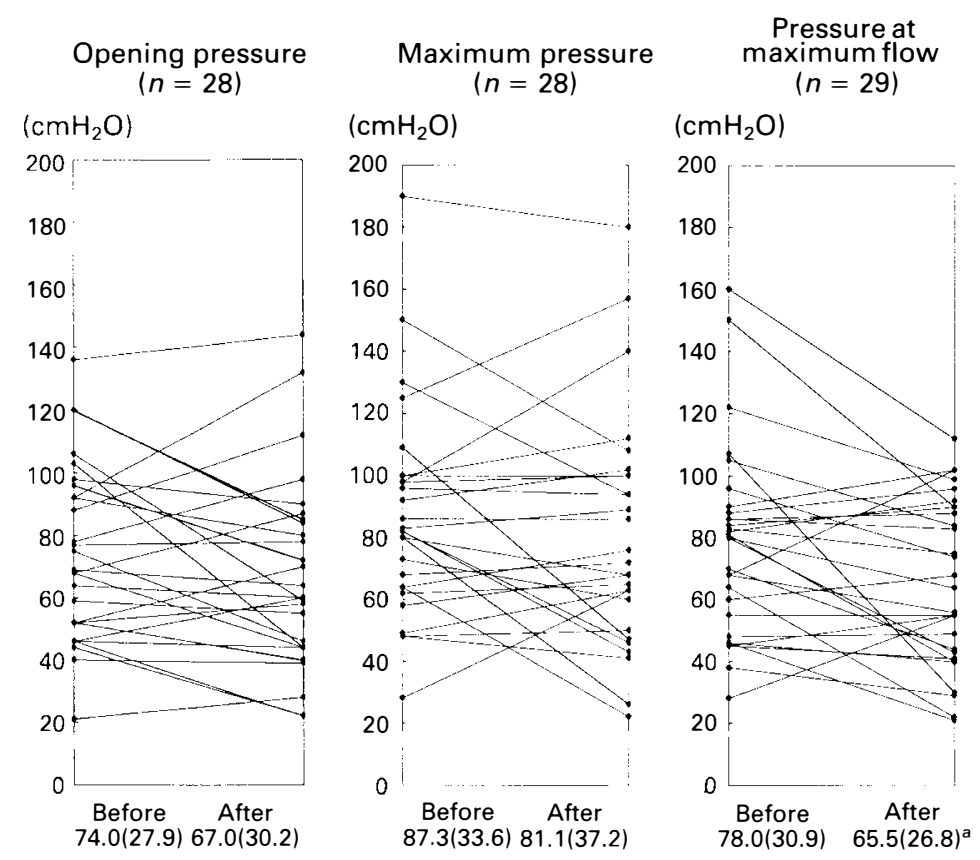
Minimum urethral resistance $(n=29)$

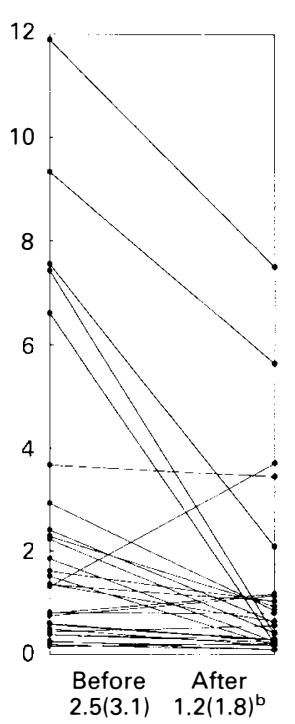

Figure 3 Changes in pressure/flow studies before and after treatment with urapidil. Values are mean (SD). ${ }^{a} p<0.05 ;{ }^{b} p<0.01$ (before and after treatment, paired $t$-test).

patients with the same conditions of voiding.

The complexity of the $\mathrm{p} / \mathrm{f}$ study seems to be one of the reasons why it is not utilised as a routine procedure to measure urethral resistance: when a hard catheter is used, insertion is painful and urine sometimes escapes out of the collecting system, and when a soft and straight feeding tube is used, it often slips out during voiding. Suprapubic puncture permits a measurement of the urethral resistance without placing any instrument in the urethra during urination, but this technique is not suitable as a routine measurement. Thus, the transurethral technique using a catheter is preferable in routine clinical practice. Iverson ${ }^{15}$ transurethrally used a modified $8.3-\mathrm{F} \mathrm{J}$ nephrostomy catheter for $\mathrm{p} / \mathrm{f}$ measurements and reported no significant differences in Qave and Qmax between the spontaneous UFM and the $\mathrm{p} / \mathrm{f}$ study. The authors do not recommend this catheter because it is relatively hard and the width affects urinary flow. ${ }^{6}$ Using a 4-F pigtail catheter, the authors could perform the $\mathrm{p} / \mathrm{f}$ study in all patients who were able to undergo cath- eter-free uroflowmetry, and the urinary flow was almost the same as that measured by the UFM.

Alpha-blockers have been reported to reduce residual urine, ${ }^{11}$ but the amount of residual urine may vary according to the patient's way of continuing straining.

Qave and Qmax are useful parameters to assess voiding difficulties, but no significant changes in Qave and Qmax were found in our previous UFM using an alpha-blocker, moxisylyte (Moxil ${ }^{\circledR}$, Fuji Revio, Japan), ${ }^{16}$ or in the present study. We thought the reason may be that Qave and Qmax may vary according to the magnitude and intermittency of straining in neuropathic bladder patients.

In the previous CMG and ES-EMG studies, bladder compliance, detrusor hyperreflexia and/or DSD improved in patients receiving alpha-blockers. ${ }^{10.16}$ These parameters are important but applicable only in patients who showed abnormal parameters before treatment. Thus these parameters cannot be applied to all patients with neuropathic bladder. Thus, the changes in $\mathrm{R}$ by measurement of the $\mathrm{p} / \mathrm{f}$ study might be 
applied in all neuropathic patients with voiding difficulty.

In the present study. PQmax and $\mathrm{R}$ decreased significantly while Qave and
Qmax did not increase significantly. These results suggest that in some patients, voiding may improve without increasing the flow rate but with decreasing straining.

\section{References}

1 Edvardsen P, Setekleiv J (1968) Distribution of adrenergic receptors in the urinary bladder of cats, rabbits and guinea-pigs. Acta pharmacol Toxicol 26: 437-445.

2 Khanna OP (1976) Disorders of micturition. Neuropharmacologic basis and results of drug therapy. Urology 8: 316-328.

3 Caine M (1986) The present role of alpha-adrenergic blockers in the treatment of benign prostatic hypertrophy. J Urol 136: 1-4.

4 Kirby RS, Coppinger SWC, Corcoran MO, Chapple CR, Flannigan M, Milroy EJG (1987) Prazosin in the treatment of prostatic obstruction. A placebo-controlled study. Br J Urol 60: 136-142.

5 Whitfield HN, Doyle PT, Mayo ME, Poopalasingham N (1976) The effect of adrenergic blocking drugs on outflow resistance. Br J Urol 47: 823-827.

6 Lenaghan D (1970) The diagnosis of prostatic obstruction by measurement of urethral resistance to flow. J Urol 103: $320-326$.

7 Kleeman FJ (1970) The physiology of the internal urinary sphincter. J Urol 104: 549-554.

8 Gerstenberg T, Blaabjerg J, Nielsen ML, Clausen S (1980) Phenoxybenzamine reduces bladder outlet obstruction in benign prostatic hyperplasia. A urodynamic investigation. Invest Urol 18: 29-32.

9 Krane RJ, Olsson CA (1973) Phenoxybenzamine in neurogenic bladder dysfunction. II. Clinical considerations. J Urol 110: 653-656.

10 Jensen Jr D (1981) Uninhibited neurogenic bladder treated with prazosin. Scand J Urol Nephrol 15: 229-233.

11 Cramer P, Neveux E, Régnier F, Depassio J, Bérard E (1989) Bladder-neck opening test in spinal cord injury patients using a new i.v. alpha-blocking agent, alfuzosin. Paraplegia 27: 119-124.

12 Yasuda K, Nagashima K, Murayama N, Yamanishi T, Tojo M, Shimazaki J (1991) Changes of external urethral sphincter function in prostatic patients. Urol Int (Suppl) 47: 43-47.

13 International Continence Society Committe on Standardization of Terminology (1988) The standardization of terminology of lower urinary tract function. Scand J Urol Nephrol (Suppl) 114: 5-19.

14 Schäfer W (1985) Urethral resistance? Urodynamic concepts of physiological and pathological bladder outlet function during voiding. Neurourol Urodyn 4: 161-201.

15 Iverson P, Jensen KME, Bruskewitz RC, Madsen PO (1983) Modified J nephrostomy for intravesical pressure measurement in urodynamics. Urology 11: 550-552.

16 Yamanishi T, Yasuda K, Murayama N, Nagashima K, Tojo M, Wada T et al (1991) Clinical effects of moxisylyte hydrochloride on micturition disturbance due to neurogenic bladder. Nishinihon J Urol 53: 283-289. 